\title{
Inhibition of Poly(ADP-Ribose) Polymerase Enhances the Toxicity of 131 I-Metaiodobenzylguanidine/Topotecan Combination Therapy to Cells and Xenografts That Express the Noradrenaline Transporter
}

\author{
Anthony G. McCluskey*1, Robert J. Mairs*2, Mathias Tesson², Sally L. Pimlott ${ }^{3}$, John W. Babich ${ }^{4}$, Mark N. Gaze ${ }^{5}$, \\ Sue Champion ${ }^{6}$, and Marie Boyd ${ }^{1}$ \\ ${ }^{1}$ Strathclyde Institute of Pharmacy and Biomedical Sciences, University of Strathclyde, Glasgow, United Kingdom; ${ }^{2}$ Centre of \\ Oncology and Applied Pharmacology, University of Glasgow, Glasgow, United Kingdom; ${ }^{3}$ West of Scotland Radionuclide Dispensary, \\ Western Infirmary, NHS Greater Glasgow and Clyde, Glasgow, United Kingdom; ${ }^{4}$ Molecular Insight Pharmaceuticals, Cambridge, \\ Massachusetts; ${ }^{5}$ Department of Oncology, University College London Hospitals, NHS Foundation Trust, London, United Kingdom; \\ and ${ }^{6}$ Institute of Neuroscience and Psychology, University of Glasgow, Glasgow, United Kingdom
}

Targeted radiotherapy using ${ }^{131} \mid \mathrm{I}$-metaiodobenzylguanidine (131 I-MIBG) has produced remissions in some neuroblastoma patients. We previously reported that combining ${ }^{131}$ I-MIBG with the topoisomerase I inhibitor topotecan induced long-term DNA damage and supraadditive toxicity to noradrenaline transporter (NAT)-expressing cells and xenografts. This combination treatment is undergoing clinical evaluation. This present study investigated the potential of poly(adenosine diphosphate [ADP]ribose) polymerase (PARP-1) inhibition, in vitro and in vivo, to further enhance ${ }^{131}$ I-MIBG/topotecan efficacy. Methods: Combinations of topotecan and the PARP-1 inhibitor PJ34 were assessed for synergism in vitro by combination-index analysis in SK-N-BE(2c) (neuroblastoma) and UVW/NAT (NAT-transfected glioma) cells. Three treatment schedules were evaluated: topotecan administered $24 \mathrm{~h}$ before, $24 \mathrm{~h}$ after, or simultaneously with PJ34. Combinations of PJ34 and ${ }^{131}$ I-MIBG and of PJ34 and ${ }^{131}$ I-MIBG/topotecan were also assessed using similar scheduling. In vivo efficacy was measured by growth delay of tumor xenografts. We also assessed DNA damage by $\gamma \mathrm{H} 2 \mathrm{~A} . \mathrm{X}$ assay, cell cycle progression by fluorescence-activated cell sorting analysis, and PARP-1 activity in treated cells. Results: In vitro, only simultaneous administration of topotecan and PJ34 or PJ34 and 131 I-MIBG induced supraadditive toxicity in both cell lines. All scheduled combinations of PJ34 and ${ }^{131} \mathrm{I}-\mathrm{MIBG} /$ topotecan induced supraadditive toxicity and increased DNA damage in SK-N-BE(2c) cells, but only simultaneous administration induced enhanced efficacy in UVW/NAT cells. The PJ34 and ${ }^{131}$ I-MIBG/ topotecan combination treatment induced $\mathrm{G}_{2}$ arrest in all cell lines, regardless of the schedule of delivery. In vivo, simultaneous administration of PJ34 and ${ }^{131} \mathrm{I}-\mathrm{MIBG} /$ topotecan significantly delayed the growth of SK-N-BE(2c) and UVW/NAT xenografts, compared with ${ }^{131} \mathrm{I}-\mathrm{MIBG} /$ topotecan therapy. Conclusion: The

Received Jul. 27, 2011; revision accepted Mar. 5, 2012.

For correspondence or reprints contact: Anthony G. McCluskey, Strathclyde Institute of Pharmacy and Biomedical Sciences, University of Strathclyde, 161 Cathedral St., Glasgow, U.K., G4 ORE.

E-mail: anthony.mccluskey@strath.ac.uk

${ }^{*}$ Contributed equally to this work.

Published online Jun. 11, 2012.

COPYRIGHT (c) 2012 by the Society of Nuclear Medicine, Inc. antitumor efficacy of topotecan, ${ }^{131}$ I-MIBG, and 131/-MIBG/ topotecan combination treatment was increased by PARP-1 inhibition in vitro and in vivo.

Key Words: combination therapy; PARP-1; targeted radionuclides J Nucl Med 2012; 53:1146-1154 DOI: 10.2967/jnumed.111.095943

$\mathbf{N}$ euroblastoma is a heterogeneous disease, and patients can be assigned to various risk groups using age, stage, and other biologic characteristics (1). There is evidence that, over time, outcomes are gradually improving (2). However, for patients with high-risk disease, outcomes remain poor $(3,4)$, and innovative therapies are required, especially for those whose disease fails to respond well to induction chemotherapy (5).

Approximately $90 \%$ of neuroblastoma tumor cells express the noradrenaline transporter (NAT), a 12-spanning integral membrane protein responsible for the active intracellular accumulation of catecholamine neurotransmitters. Metaiodobenzylguanidine (MIBG), a derivative of the adrenergic neurone-blocking drugs bretylium and guanethidine, is a structural analog of noradrenaline and is also selectively concentrated in NAT-expressing tissues and tumors by this process $(6,7)$.

Targeted therapy of neuroblastoma using ${ }^{131}$ I-MIBG has produced encouraging results (long-term remissions and palliation) in patients with resistant disease $(8-10)$. However, the most effective way to use this drug has yet to be defined, and, increasingly, ${ }^{131}$ I-MIBG is administered in combination with other treatments $(11,12)$. The optimization of radiation damage induced in target cells can be obtained by the rational combination of ${ }^{131}$ I-MIBG with radiosensitizing agents, and we have previously reported that pretreatment with the topoisomerase I (Topo-I) poison 
topotecan increased the intracellular concentration of ${ }^{131} \mathrm{I}-$ MIBG (13). Furthermore, we demonstrated that combinations of ${ }^{131} \mathrm{I}-\mathrm{MIBG}$ and topotecan induced disruption of DNA repair in NAT-expressing cells in vitro, increased supraadditive levels of cytotoxicity, and increased efficacy against NAT-expressing xenografts in vivo. Maximal topotecan-induced radiosensitization resulted from the administration of the drug simultaneously with or after ${ }^{131} \mathrm{I}-$ MIBG. Exposure to topotecan before ${ }^{131} \mathrm{I}-\mathrm{MIBG}$ was less effective $(14,15)$, suggesting that increased ${ }^{131}$ I-MIBG uptake due to prior topotecan administration was less important an influence on efficacy than the increased disruption of DNA repair observed in cells treated by combination schedules where topoisomerase I was inhibited concurrently, or after ${ }^{131} \mathrm{I}-\mathrm{MIBG}$ administration.

On the basis of our findings, clinical investigations of MATIN (MIBG and Topotecan in Neuroblastoma) have commenced (16). To date, more than 70 patients in 5 institutions across Europe have been enrolled in MATIN. Encouraging responses have been observed in a heterogeneous group of patients with relapsed or primary refractory disease. It is our intention to further enhance the effectiveness of MATIN by identifying other clinically relevant drugs that synergize with topotecan, ${ }^{131} \mathrm{I}-\mathrm{MIBG}$, or both agents combined.

Poly(adenosine diphosphate [ADP]-ribose) polymerase (PARP-1) is an enzyme involved in DNA repair $(17,18)$, and PARP-1 inhibition has been shown to enhance the efficacy of low-dose radiation (19). Furthermore, PARP-1 binds directly to Topo-I, leading to increased formation of Topo-I-DNA complexes (20). Therefore, we conjectured that PARP-1 inhibition may also influence topotecan-induced toxicity. This study investigated the effects of PARP-1 inhibition on the efficacy of topotecan, ${ }^{131} \mathrm{I}-\mathrm{MIBG}$, and ${ }^{131} \mathrm{I}-\mathrm{MIBG} /$ topotecan combination therapy.

\section{MATERIALS AND METHODS}

\section{Drugs}

Topotecan (topoisomerase I inhibitor) was purchased from Axxora (U.K.) Ltd. and PJ34 (PARP-1 inhibitor) from Merck Chemicals Ltd. For in vitro experiments, no-carrier-added ${ }^{131} \mathrm{I}-$ MIBG was provided by Dr. Sally Pimlott, NHS Greater Glasgow and Clyde. For in vivo experiments, no-carrier-added ${ }^{131}$ I-MIBG was provided by Molecular Insight Pharmaceuticals Inc.

\section{Cells and Culture Conditions}

The following human cell lines were cultured: SK-N-BE(2c), derived from neuroblastoma (21), and UVW/NAT, derived by transfection of the noradrenaline transporter gene into the human glioma cell line UVW (22). UVW/NAT cells were maintained in modified Eagle medium containing $10 \%$ fetal calf serum and $2 \mathrm{mM}$ glutamine. SK-N-BE(2c) cells were maintained in Dulbecco modified Eagle medium containing $15 \%$ fetal calf serum, nonessential amino acids, and $2 \mathrm{mM}$ glutamine. Cell lines were maintained at $37^{\circ} \mathrm{C}$ in a $5 \% \mathrm{CO}_{2}$ atmosphere. All media and supplements were purchased from Gibco. Cell lines were authenticated routinely using the Applied Biosystems AmpF/STR Identifiler Kit (Applied Biosystems U.K.).

\section{No-Carrier-Added Synthesis of ${ }^{131}$ I-MIBG via Polymer-Supported Precursor}

For in vivo experiments, no-carrier-added ${ }^{131} \mathrm{I}$-MIBG was prepared using a solid-phase system for which the precursor of ${ }^{131} \mathrm{I}$ MIBG was attached to an insoluble polymer via the tin-aryl bond $(23,24)$. For in vitro experiments, no-carrier-added ${ }^{131}$ I-MIBG was prepared using a liquid phase system, with the trimethylsily precursor $(\mathrm{ABX})(25)$. The reaction conditions, high-performance liquid chromatography purification procedure, and radiochemical yield were as described previously (24).

\section{Determination of Cytotoxicity After Combination Therapy}

To investigate the effects of PARP-1 inhibition on ${ }^{131}$ I-MIBG/ topotecan therapy, initially combinations of topotecan and PJ34 were evaluated using the following 3 treatment schedules: topotecan administered $24 \mathrm{~h}$ before PJ34 (schedule 1), topotecan administered after PJ34 (schedule 2), or topotecan administered simultaneously with PJ34 (schedule 3).

Combinations of PJ34 and ${ }^{131} \mathrm{I}-\mathrm{MIBG}$ and triple combinations of PJ34 and ${ }^{131} \mathrm{I}-\mathrm{MIBG} /$ topotecan were also evaluated, using similar scheduling. Because we have already reported that the administration of ${ }^{131} \mathrm{I}-\mathrm{MIBG}$ and topotecan induced supraadditive responses, in the assessment of PJ34, ${ }^{131} \mathrm{I}-\mathrm{MIBG}$, and topotecan 3-drug combinations, PJ34 was administered $24 \mathrm{~h}$ before, after, or simultaneously with ${ }^{131} \mathrm{I}-\mathrm{MIBG}$ and topotecan given simultaneously.

Cytotoxicity was measured by clonogenic assay. Monolayers of cells were cultured in $25-\mathrm{cm}^{2}$ flasks (Nunclon Plastics). UVW/NAT and SK-N-BE(2c) cells were seeded at $2 \times 10^{5}$ and $4 \times 10^{5}$ cells per flask, respectively. After $2 \mathrm{~d}$, when the cultures were $70 \%$ confluent, medium was removed and replaced with fresh medium containing the appropriate concentration of test drug. Cells were incubated with ${ }^{131}$ I-MIBG for $2 \mathrm{~h}$, after which uptake is maximal (26). Cells were incubated with topotecan or PJ34 for $24 \mathrm{~h}$.

After experimental therapy, cells were washed twice in phosphate-buffered saline (PBS), detached by treatment with $0.05 \%$ (v/v) trypsin-ethylenediaminetetraacetic acid (Gibco), and counted and seeded, in triplicate, in $60 \times 15 \mathrm{~mm}$ plastic dishes (Nunclon Plastics) at $2.5 \times 10^{2}$ cells per dish, for every test concentration. Cultures were incubated at $37^{\circ} \mathrm{C}$ in $5 \% \mathrm{CO}_{2}$ for $14 \mathrm{~d}$. Colonies were fixed in $100 \%$ methanol and visualized by staining with a solution of $1 \%(\mathrm{v} / \mathrm{v})$ Giemsa (BDH Laboratory Supplies) and counted.

\section{Synergy Analysis}

The efficacy of the various scheduled combinations was examined according to the method of Chou and Talalay, which is based on the median-effect principle (27). Briefly, from the results of clonogenic assays, dose-effect curves were plotted using the equation $\log [f a / f u]=m \log D-m \log \mathrm{IC}_{50}$, where $D$ is the drug dose; $f a$ and $f u$ are, respectively, the fraction of cells affected by drug dose $D$ and the unaffected fraction, and $\mathrm{IC}_{50}$ is the dose that inhibited $50 \%$ of colony formation. From these survival plots, the $x$-intercept $\left(\log \left[\mathrm{IC}_{50}\right]\right)$ and slope $m$ were generated for each treatment. These parameters were used to calculate $D$, the doses of component agents (and combinations) required to produce various levels of toxicity.

The effectiveness of combination therapy was then assessed by combination-index (CI) analysis (27). The toxicities induced by single drugs and scheduled combinations were investigated using the equation $\mathrm{CI}=(D)_{1} /(D \mathrm{x})_{1}+(D)_{2} /(D \mathrm{x})_{2}$, where $(D)_{1}$ and $(D)_{2}$ are the doses of each agent that inhibit $\mathrm{x} \%$ of cell growth when 
used in combination, and $(D \mathrm{x})_{1}$ and $(D \mathrm{x})_{2}$ are the doses of each drug, administered as single agents, that inhibit $\mathrm{x} \%$ of colonies. The resultant numeric values, the combination indices, were plotted against toxicity level.

\section{Assessment of Cell Cycle Progression by Fluorescence-Activated Cell Sorting Analysis}

Cells were plated in $25-\mathrm{cm}^{2}$ flasks and exposed to single drug and multidrug combinations as described above. To directly compare the effects on cell cycle progression with the results of clonogenic assay, the same drug concentrations and incubation times were used. Cultures were then trypsinized, counted, washed twice with PBS, and resuspended in PBS at a concentration of $1 \times 10^{6}$ cells $/ \mathrm{mL}$. Cells were fixed by treatment with $75 \%(\mathrm{v} / \mathrm{v})$ ethanol for $1 \mathrm{~h}$ at $4^{\circ} \mathrm{C}$. Fixed cells were washed twice with PBS and resuspended in $1 \mathrm{~mL}$ of PBS containing $50 \mathrm{mg}$ of propidium iodide per milliliter (Sigma Chemicals) and $5 \mu \mathrm{g}$ of RNase A per milliliter (Qiagen Ltd.). Cells were stained for $3 \mathrm{~h}$ at $4^{\circ} \mathrm{C}$ before flow cytometry, using a FACScan analyzer (Becton Dickinson Systems). Data were analyzed using CellQuest Pro software (version 5.1.1; BD Biosciences).

\section{Assessment of Double-Strand (ds) DNA Breaks by H2A.X Phosphorylation}

Phosphorylation of histone H2A.X at serine $139(\gamma \mathrm{H} 2 \mathrm{~A} . \mathrm{X})$ was assessed using the H2A.X phosphorylation assay kit (Millipore). Briefly, cells were seeded and drug-treated, as described above. Immediately after treatment, when DNA damage was expected to be maximal, cells were trypsinized, counted, washed twice with PBS, and fixed by addition of formaldehyde and methanol for $20 \mathrm{~min}$ at $4^{\circ} \mathrm{C}$. Cells were then washed 3 times with PBS and resuspended, at a concentration of $2 \times 10^{6}$ cells $/ \mathrm{mL}$, in permeabilization solution (5\% saponin; $100 \mathrm{mM} N$-[2-hydroxyethyl] piperazine- $N^{\prime}$-[2-ethanesulfonic acid], $\mathrm{pH} 7.4 ; 1.4 \mathrm{M} \mathrm{NaCl}$; and $25 \mathrm{mM} \mathrm{CaCl}_{2}$ ) containing antiphospho-histone H2A.X (Ser139)fluorescein isothiocyanate conjugate for $20 \mathrm{~min}$ at $4^{\circ} \mathrm{C}$. Fluorescence was measured using a FACScan analyzer, and data were analyzed using CellQuest Pro software, version 5.1.1.

\section{PARP-1 Assay}

Cellular PARP-1 activity was assessed using the commercially available HT Universal colorimetric assay kit (AMS Biotechnology Ltd.), according to the manufacturer's instructions. Briefly, following the drug treatment as described in the "Determination of Cytotoxicity After Combination Therapy" section, PARP-1 activity was assayed by incorporation of biotinylated poly(ADP-ribose) onto histone proteins, followed by incubation with streptavidinhorseradish peroxidase and TACS (Trevigen Apoptotic Cell System; Trevigen) sapphire colorimetric substrate. Absorbance at 450 $\mathrm{nm}$ was measured using a Sunrise plate reader (Tecan U.K. Ltd.), with Magellan CE software (version 5.04).

\section{Experimental Animals}

Six-week-old female, congenitally athymic nude mice of strain MF1 $n u / n u$ were obtained from Charles River PLC. Experiments were performed in accordance with the U.K. Coordinating Committee on Cancer Research guidelines (28).

\section{In Vivo Investigations}

SK-N-BE(2c) and UVW/NAT xenografts were established and analyzed as previously described $(14,15)$. Briefly, SK-N-BE(2c) xenografts were established by intrasplenic injection of $3 \times 10^{6}$ exponentially growing cells. After the growth of tumors in the spleen and liver, animals were euthanized and tumor fragments 2-3 $\mathrm{mm}$ in diameter were then implanted subcutaneously in the subcostal flanks of other nude mice. Experimental therapy commenced $17 \mathrm{~d}$ after tumor implantation when tumors had reached approximately $10 \mathrm{~mm}$ in diameter $\left(500 \mathrm{~mm}^{3}\right)$. UVW/NAT xenografts were established by subcutaneous injection of $2 \times 10^{6}$ cells. Experimental therapy was initiated $9 \mathrm{~d}$ later, when tumor volume was approximately $60 \mathrm{~mm}^{3}$.

Groups of 6 mice with SK-N-BE(2c) or UVW/NAT tumors were randomized into 6 treatment groups that received, by intraperitoneal injection, saline (control), PJ34 (20 mg/kg) alone, $18 \mathrm{MBq}$ of ${ }^{131} \mathrm{I}-\mathrm{MIBG}$ plus $1.75 \mathrm{mg}$ of topotecan per kilogram (SK-N-BE(2c)), $5 \mathrm{MBq}$ of ${ }^{131} \mathrm{I}-\mathrm{MIBG}$ plus $0.825 \mathrm{mg}$ of topotecan per kilogram (UVW/NAT), or PJ34 given simultaneously with ${ }^{131} \mathrm{I}-\mathrm{MIBG} /$ topotecan.

Experimental xenografts were measured with calipers immediately before treatment and every 2-3 d thereafter. Measurements were converted to an approximate volume on the assumption of ellipsoidal geometry as previously described $(14,15)$.

For each treatment group, the mean time taken for a 2-fold $\left(T_{2}\right)$ (SK-N-BE(2c)) or 10-fold $\left(T_{10}\right)$ (UVW/NAT) increase in tumors was calculated. Tumor cure was defined as the failure of experimental xenografts to grow over the experimental time course.

\section{Statistical Analysis}

Unless otherwise stated, experimental results are expressed as means and SDs of 3 separate experiments, performed in triplicate. Statistical analyses were performed using Prism software (version 4.03; GraphPad Software Inc.). One-way ANOVA was used to compare, between treatments, formation of dsDNA damage and PARP-1 activity. Post hoc testing used Bonferroni correction for multiple comparisons. Differences in tumor growth between experimental therapy groups were assessed by the Kruskal-Wallis test, followed by post hoc testing by the Mann-Whitney $U$ test. With Bonferroni correction, a $P$ value of less than 0.01667 was considered significant.

\section{RESULTS}

\section{Cytotoxicity of 2-Drug Combination Therapy}

For both cell lines, the efficacy of topotecan and PJ34 as single agents was assessed, and results were plotted graphically, according to the median-effect principle (Supplemental Fig. 1A; supplemental materials are available online only at http://jnm.snmjournals.org). On the basis of single-drug toxicity, a fixed ratio of topotecan-to-PJ34 was used in subsequent analyses of alternative combination schedules. The topotecan $(\mathrm{nM})$-to-PJ34 $(\mu \mathrm{M})$ ratios were 8.8:31.97 for SK-N-BE(2c) cells and 10:29.1 for UVW/ NAT cells. The median-effect plots for alternative topotecan and PJ34 combination schedules are shown in Supplemental Figure 1B.

Combination-index analysis of topotecan and PJ34 treatments in SK-N-BE(2c) and UVW/NAT cells are shown in Figure 1. Both cell lines were resistant to doses of combinations of topotecan and PJ34, which induced low levels of toxicity. Schedule 3 (topotecan and PJ34 simultaneously) was the most effective treatment, inducing supraadditive responses in both lines. In SK-N-BE(2c) cells, supraadditive responses were also observed after the administration of 


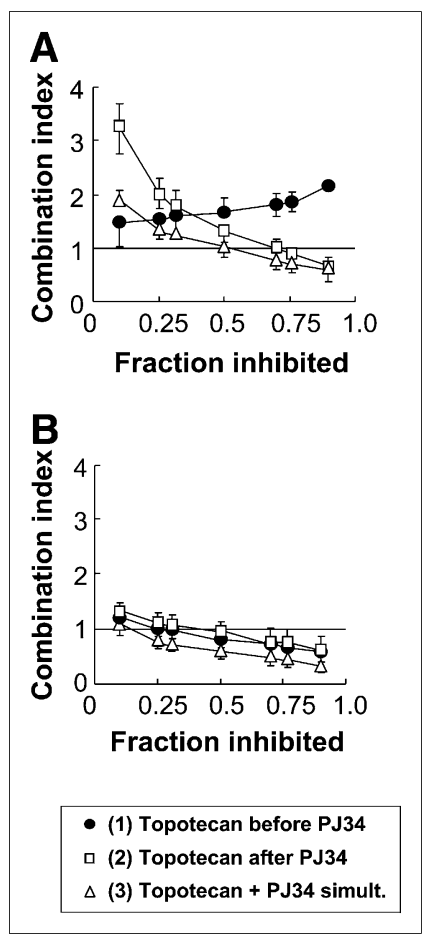

FIGURE 1. Combination-index analysis of PJ34/topotecan treatment in SK-N-BE(2C) (A) and UVW/NAT (B) cells. On the basis of results shown in Supplemental Figure 1, SK-N-BE (2c) cells were treated with topotecan and PJ34 in a ratio of 8.8:31.97. UVW/NAT cells were treated with PJ34 and topotecan in a ratio of 10:29.1. Data are means and SDs of triplicate determinations from 3 experiments. $\mathrm{Cl}<1, \mathrm{Cl}=1$, and $\mathrm{Cl}>1$ indicate synergism, additivity, and antagonism, respectively.

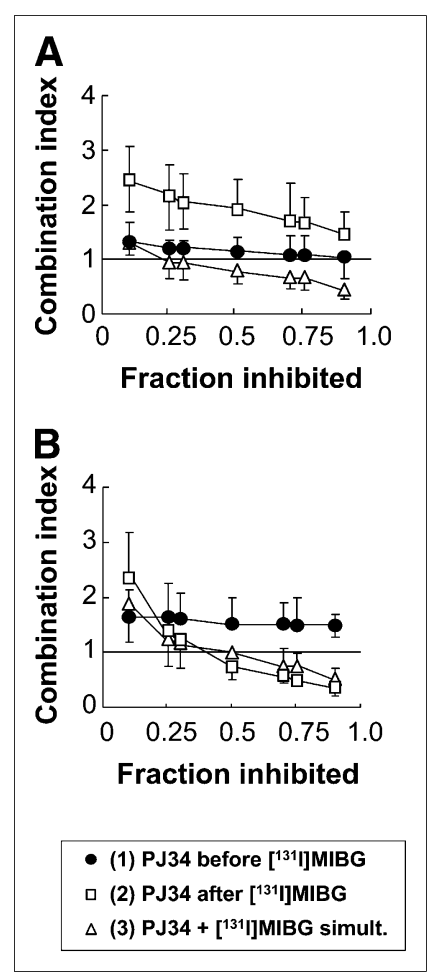

FIGURE 2. Combination-index analysis of $\mathrm{PJ} 34 /{ }^{131} \mid-$ MIBG treatment in SK-N-BE (2c) (A) and UVW/NAT (B) cells. On the basis of results shown in Supplemental Figure 2, SK$\mathrm{N}-\mathrm{BE}(2 \mathrm{c})$ cells were treated with PJ34 and ${ }^{131}$ I-MIBG in a ratio of 31.97:1.29. UVW/ NAT cells were treated with PJ34 and ${ }^{131}$ I-MIBG in a ratio of 29.1:2.76. Data are means and SDs of triplicate determinations from 3 experiments. $\mathrm{Cl}$ $<1, \mathrm{Cl}=1$, and $\mathrm{Cl}>1$ indicate synergism, additivity, and antagonism, respectively.

schedule 2 treatment (topotecan after PJ34, but not schedule 1, topotecan before PJ34). All 3 schedules induced supraadditivity in UVW/NAT cells at high levels of toxicity.

Dose responses for PJ34 and ${ }^{131} \mathrm{I}-\mathrm{MIBG}$ as single agents are shown in Supplemental Figure 2A. On the basis of these results, the ratios of PJ34 $(\mu \mathrm{M})-$ to- ${ }^{131}$ I-MIBG $(\mathrm{MBq} / \mathrm{mL})$ used in subsequent combination studies were 31.97:1.29 for SK-N-BE(2c) cells and 29.1:2.76 for UVW/NAT cells. The effects of scheduled combinations are shown in Supplemental Figure 2B. The resultant combination-index analyses of SK-N-BE(2c) and UVW/NAT cells are shown in Figure 2.

Both cell lines were resistant to doses of combinations of PJ34 and ${ }^{131}$ I-MIBG, which induced low levels of toxicity. Schedule 3 (PJ34 and ${ }^{131}$ I-MIBG simultaneously) induced supraadditive responses in both cell lines. In SK-N-BE(2c) cells, schedule 1 (PJ34 before ${ }^{131}$ I-MIBG) induced an additive response, whereas schedule 2 (PJ34 after ${ }^{131}$ I-MIBG) induced infraadditive toxicity. In UVW/NAT cells, supraadditive responses were also observed after administration of schedule 2 , whereas schedule 1 induced infraadditive toxicity.

\section{Cytotoxicity of 3-Drug Combination Therapy}

Dose responses for PJ34 as a single agent and ${ }^{131} \mathrm{I}-$ MIBG/topotecan 2-drug combinations are shown in Supplemental Figure 3A. On the basis of these results, the ratios of PJ34 $(\mu \mathrm{M})$ to ${ }^{131} \mathrm{I}-\mathrm{MIBG}(\mathrm{MBq} / \mathrm{mL})$ to topotecan $(\mathrm{nM})$ used in subsequent 3-drug combination studies were 31.97:1.29:8.8 for SK-N-BE(2c) cells and 29.1:2.76:10 for UVW/NAT cells. Therefore, 1 arbitrary dose unit (au) contained $0.76 \mu \mathrm{M}$ PJ34, $0.03 \mathrm{MBq}$ of ${ }^{131} \mathrm{I}$-MIBG per milliliter, and $0.21 \mathrm{nM}$ topotecan for SK-N-BE(2c) cells, or

$0.69 \mu \mathrm{M}$ PJ34, $0.07 \mathrm{MBq}$ of ${ }^{131} \mathrm{I}-\mathrm{MIBG}$ per milliliter, and $0.24 \mathrm{nM}$ topotecan for UVW/NAT cells.

The effects of scheduled triple combinations are shown in Supplemental Figure 3B. The resultant combination-index analyses of SK-N-BE(2c) and UVW/NAT cells are shown in Figure 3.

Supraadditive toxicity was observed in SK-N-BE(2c) cells following all 3 schedules at every level of toxicity assessed. Only schedule 3 (PJ34 and ${ }^{131} \mathrm{I}-\mathrm{MIBG} /$ topotecan

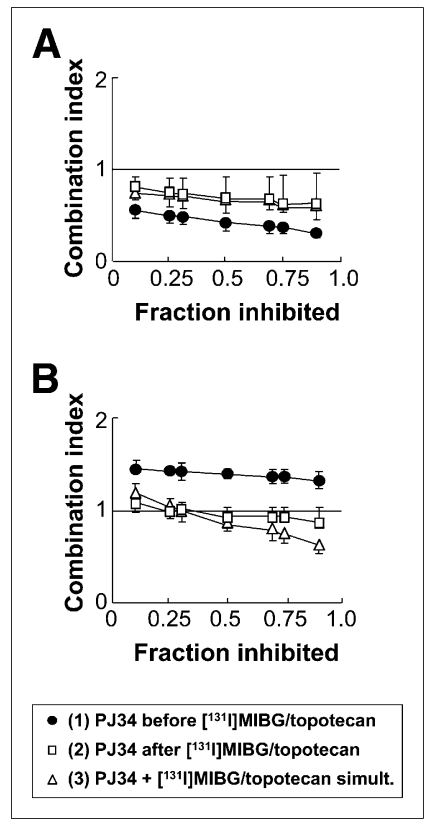

FIGURE 3. Combination index analysis of PJ34/131IMIBG/topotecan in SK-N-BE (2c) (A) and UVW/NAT (B) cells. On the basis of results shown in Supplemental Figure 3, SK$\mathrm{N}-\mathrm{BE}(2 \mathrm{c})$ cells were treated with PJ34, ${ }^{131} \mathrm{I}-\mathrm{MIBG}$, and topotecan in a ratio of 31.97:1.29:8.8. UVW/NAT cells were treated with PJ34, ${ }^{131}$ IMIBG, and topotecan in a ratio of 29.1:2.76:10. Data are means and SDs of triplicate determinations from 3 experiments. $\mathrm{Cl}<1, \mathrm{Cl}=1$, and $\mathrm{Cl}>1$ indicate synergism, additivity, and antagonism, respectively. 
simultaneously) induced enhanced efficacy in UVW/NAT cells. Schedule 2 (PJ34 after ${ }^{131}$ I-MIBG/topotecan) induced an additive response in UVW/NAT cells, whereas schedule 1 (PJ34 before ${ }^{131} \mathrm{I}-\mathrm{MIBG} /$ topotecan) was antagonistic.

\section{Cell Cycle Redistribution}

Cell cycle redistribution induced by PJ34 in SK-N-BE (2c) and UVW/NAT cells is shown in Table 1. The effects of triple-combination treatments on cell cycle phases are shown in Tables 2 (SK-N-BE(2c)) and 3 (UVW/NAT). PJ34 as a single agent induced $\mathrm{G}_{2} / \mathrm{M}$ arrest. Likewise, all 3 scheduled combinations of PJ34 and ${ }^{131} \mathrm{I}-\mathrm{MIBG} /$ topotecan caused an increase in the number of cells in $\mathrm{G}_{2} / \mathrm{M}$.

\section{$\gamma \mathrm{H} 2 \mathrm{~A} . \mathrm{X}$ Analysis of dsDNA Damage}

The effects of 3-drug administration on formation of dsDNA breaks are shown in Figure 4A. Cells treated with PJ34 and ${ }^{131} \mathrm{I}-\mathrm{MIBG} /$ topotecan combinations displayed increased phosphorylation of H.2AX foci compared with untreated controls. In $\mathrm{SK}-\mathrm{N}-\mathrm{BE}(2 \mathrm{c})$ cells, all treatment schedules induced a 28- to 45-fold increase in dsDNA damage. ANOVA demonstrated no significant difference between the potency of alternative combination schedules. However, in UVW/NAT cells, administration of alternative schedules gave rise to various levels of DNA damage. Schedule 1 induced a 2-fold increase in $\gamma \mathrm{H} 2 \mathrm{~A} . \mathrm{X}$ foci, whereas schedule 3 induced a 60 -fold increase. Schedule 2 induced a 20-fold increase in H2A.X phosphorylation. ANOVA demonstrated significant variation between the responses induced by alternative schedules of delivery and in post hoc testing. Schedule 3 induced significantly higher levels of $\gamma \mathrm{H} 2 \mathrm{~A}$.X phosphorylation than either of the other treatment schedules $(P<0.01667)$.

\section{PARP-1 Activity}

The effects of PJ34 treatment and ${ }^{131} \mathrm{I}-\mathrm{MIBG} /$ topotecan 2-drug therapy on PARP-1 activity in SK-N-BE(2c) and UVW/NAT cells are shown in Figure 4B. PJ34 induced a dose-dependent reduction in PARP-1 activity, compared with untreated controls. SK-N-BE(2c) cells were more sensitive to PJ34 than UVW/NAT cells. The dose that reduced PARP-1 activity by $50 \%\left(\mathrm{EC}_{50}\right)$ was 8.8 and $14.6 \mu \mathrm{M}$ in SK-N-BE(2c) cells and UVW/NAT cells, respectively.
In SK-N-BE(2c) cells, compared with untreated controls, administration of ${ }^{131} \mathrm{I}-\mathrm{MIBG} /$ topotecan induced a reduction in PARP-1 activity at concentrations less than or equal to 5.05 au. ${ }^{131} \mathrm{I}-\mathrm{MIBG} /$ topotecan also reduced PARP-1 activity in UVW/NAT cells at concentrations less than or equal to 6.38 au. As with PJ34, SK-N-BE(2c) cells were more sensitive to ${ }^{131} \mathrm{I}-\mathrm{MIBG} /$ topotecan than UVW/NAT cells $\left(\mathrm{EC}_{20}\right.$ values were 1.65 and 4.4 au for SK-N-BE(2c) and UVW/ NAT cells, respectively). However, in both cell lines, after administration of the highest administered dose of ${ }^{131} \mathrm{I}-$ MIBG/topotecan (7.57 au for SK-N-BE(2c) cells and 9.57 au for UVW/NAT cells), $100 \%$ recovery of PARP-1 activity was observed, suggesting an adaptive response to ${ }^{131} \mathrm{I}-$ MIBG/topotecan-induced disruption of PARP-1 function.

The effects of PJ34 and ${ }^{131} \mathrm{I}-\mathrm{MIBG} /$ topotecan combination therapy on PARP-1 activity in SK-N-BE(2c) and UVW/NAT cells are shown in Figure 4C. Three-drug therapy reduced PARP-1 activity in SK-N-BE(2c) cells, compared with untreated controls. Schedule 3 (simultaneous administration) was the most effective schedule. However, unlike ${ }^{131} \mathrm{I}-\mathrm{MIBG} /$ topotecan 2-drug therapy, there was no recovery in PARP-1 activity at higher doses in SK-N-BE (2c) cells. In UVW/NAT cells, the administration of schedules 2 and 3 (PJ34 simultaneously with or after ${ }^{131}$ I-MIBG/ topotecan) also induced a reduction in PARP-1 activity. Again, there was no evidence of a recovery of PARP-1 function at higher doses. However, schedule 1 (PJ34 before ${ }^{131} \mathrm{I}-\mathrm{MIBG} /$ topotecan) had no effect on PARP-1 activity, suggesting that inhibition of PARP-1 function by PJ34 was not only reversed after removal of the drug but also provoked resistance to subsequent ${ }^{131} \mathrm{I}-\mathrm{MIBG} /$ topotecaninduced inhibition of PARP-1 function in this cell line.

\section{In Vivo Investigations}

None of the animals in this study showed signs of distress. Figure 5 shows the effect on the growth of SK-N$\mathrm{BE}(2 \mathrm{c})$ and UVW/NAT tumor xenografts of the administration of PJ34 or ${ }^{131} \mathrm{I}-\mathrm{MIBG} /$ topotecan either alone or in combination. Tumor growth times and cure rates for SK-N$\mathrm{BE}(2 \mathrm{c})$ and UVW/NAT xenografts are presented in Table 4.

For both xenograft models, overall differences in the effectiveness of the different treatments were highly

TABLE 1

Effects of PJ34 on Cell Cycle of SK-N-BE(2c) and UVW/NAT Cells

\begin{tabular}{cccrrr}
\hline Cell line & Dose $(\mu \mathrm{M})$ & $\mathrm{G}_{1}$ & $\mathrm{~S}$ & $\mathrm{G}_{2} / \mathrm{M}$ & Sub $\mathrm{G}_{1}$ \\
\hline SK-N-BE(2c) & 0 & $66.3(1.2)$ & $8.5(2.6)$ & $21.1(3.1)$ & $0.6(0.1)$ \\
& 15 & $62.9(0.6)$ & $9.2(0.5)$ & $22.9(0.4)$ & $1.2(0.2)$ \\
& 25 & $41.2(0.6)$ & $13.5(0.6)$ & $33.7(0.3)$ & $4.0(0.5)$ \\
UVW/NAT & 40 & $28.4(0.4)$ & $16.8(0.8)$ & $40.1(0.3)$ & $7.1(0.5)$ \\
& 0 & $61.0(1.3)$ & $12.3(0.3)$ & $24.7(1.9)$ & $0.8(0.1)$ \\
& 15 & $48.4(3.6)$ & $11.3(0.9)$ & $31.2(3.9)$ & $6.7(0.4)$ \\
& 25 & $39.1(6.3)$ & $11.3(0.9)$ & $35.2(4.4)$ & $10.1(0.5)$ \\
& 40 & $37.1(0.8)$ & $17.0(0.1)$ & $37.6(1.2)$ & $3.3(1.2)$
\end{tabular}

Data are mean, followed by SD in parentheses. 
TABLE 2

Effects of PJ34 and ${ }^{131}$ I-MIBG/Topotecan on Cell Cycle of SK-N-BE(2c) Cells

\begin{tabular}{|c|c|c|c|c|c|}
\hline Treatment & Dose (au) & $\mathrm{G}_{1}$ & $\mathrm{~S}$ & $\mathrm{G}_{2} / \mathrm{M}$ & Sub $\mathrm{G}_{1}$ \\
\hline \multirow[t]{4}{*}{ Schedule 1} & 0 & $68.5(1.8)$ & $6.5(1.1)$ & $22.0(1.7)$ & $2.0(0.1)$ \\
\hline & 10.52 & $57.7(2.4)$ & $6.8(0.6)$ & 25.1 (3.9) & $1.6(1.1)$ \\
\hline & 21.03 & $50.0(7.5)$ & $6.8(0.8)$ & $33.0(6.3)$ & $8.1(0.6)$ \\
\hline & 31.55 & $37.3(5.6)$ & $9.4(2.3)$ & $40.0(4.5)$ & $10.0(3.0)$ \\
\hline \multirow[t]{4}{*}{ Schedule 2} & 0 & 66.7 (1.1) & $8.4(1.0)$ & $23.1(2.2)$ & $1.5(0.1)$ \\
\hline & 10.52 & $58.9(4.2)$ & $12.3(4.8)$ & $26.0(3.1)$ & $2.9(0.7)$ \\
\hline & 21.03 & $47.0(3.5)$ & $10.5(2.3)$ & $27.4(2.8)$ & $4.3(0.2)$ \\
\hline & 31.55 & $38.0(3.9)$ & $10.4(2.4)$ & $33.0(3.7)$ & $6.0(2.4)$ \\
\hline \multirow[t]{4}{*}{ Schedule 3} & 0 & $66.2(4.4)$ & $7.7(0.9)$ & 21.9 (3.3) & $1.6(0.4)$ \\
\hline & 10.52 & 63.7 (1.6) & 7.9 (0.3) & $25.1(2.2)$ & $2.6(0.3)$ \\
\hline & 21.03 & $42.8(2.0)$ & $10.2(4.2)$ & $34.0(3.3)$ & $12.6(4.5)$ \\
\hline & 31.55 & $37.4(3.2)$ & $8.2(0.7)$ & $41.7(0.8)$ & $12.2(0.4)$ \\
\hline
\end{tabular}

Data are mean, followed by SD in parentheses.

significant (Kruskal-Wallis test, $P<0.005$ ). Single treatment with PJ34 did not significantly affect tumor growth. Treatment with ${ }^{131} \mathrm{I}-\mathrm{MIBG} /$ topotecan or PJ34 in combination with ${ }^{131}$ I-MIBG/topotecan significantly delayed SK-N$\mathrm{BE}(2 \mathrm{c})$ and UVW/NAT tumor growth, compared with PBS-treated controls ( $P<0.01667)$. Furthermore, 3-drug therapy also significantly increased the delay in tumor growth, compared with ${ }^{131} \mathrm{I}-\mathrm{MIBG} /$ topotecan double combinations in both in vivo models $(P<0.01667)$. No SK-N$\mathrm{BE}(2 \mathrm{c})$ tumors were cured during the course of these experiments. In contrast, $60 \%$ of UVW/NAT tumors were cured by ${ }^{131} \mathrm{I}-\mathrm{MIBG} /$ topotecan treatment, whereas 3-drug treatment cured all UVW/NAT tumors.

\section{DISCUSSION}

Previously, we reported that topotecan (topoisomerase I inhibitor) synergized with ${ }^{131} \mathrm{I}-\mathrm{MIBG}$. The present study indicated that PJ34 enhanced the efficacy of topotecan and ${ }^{131} \mathrm{I}-\mathrm{MIBG}$ in vitro and ${ }^{131} \mathrm{I}$-MIBG/topotecan combination therapy in vitro and in vivo. Enhanced ${ }^{131} \mathrm{I}-\mathrm{MIBG} /$ topotecan efficacy was associated with disruption of PARP-1 activity, increased formation of dsDNA breaks, and $\mathrm{G}_{2} / \mathrm{M}$ cell cycle arrest.

Enhanced efficacy was most likely caused by disruption of DNA damage repair pathways. PARP-1 is involved in the repair of single-strand DNA breaks through the base excision repair pathway (18) and may also be involved in repair of double-strand breaks, through the homologous recombination (HR) pathway (29). Furthermore, we have previously demonstrated that topotecan and ${ }^{131} \mathrm{I}-\mathrm{MIBG}$, either alone or in combination, induced $\mathrm{G}_{2}$-phase cell cycle arrest (15). In this study, treatment with PJ34 either as a single agent or in combination with ${ }^{131} \mathrm{I}-\mathrm{MIBG} /$ topotecan also caused $\mathrm{G}_{2}$ arrest. Cells in $\mathrm{G}_{2^{-}}$and $\mathrm{M}$-phase are more radiosensitive than cells in other phases of the cell cycle (30). Thus, cell cycle redistribution induced by treatment with PJ34 and ${ }^{131}$ I-MIBG/topotecan combinations probably contributed to the enhanced efficacy of ${ }^{131} \mathrm{I}-\mathrm{MIBG}$.

After topotecan treatment, Topo-I becomes strongly associated with DNA via stabilization of Topo-I-DNA complexes, leading to stalled DNA replication. PARP-1-mediated ADP-ribosylation of Topo-I reprograms the trapped

TABLE 3

Effects of PJ34 and ${ }^{131}$ I-MIBG/Topotecan on Cell Cycle of UVW/NAT Cells

\begin{tabular}{|c|c|c|c|c|c|}
\hline Treatment & Dose (au) & $\mathrm{G}_{1}$ & $\mathrm{~S}$ & $\mathrm{G}_{2} / \mathrm{M}$ & sub $G_{1}$ \\
\hline \multirow[t]{4}{*}{ Schedule 1} & 0 & $60.3(2.2)$ & $11.4(2.6)$ & $26.9(0.7)$ & $0.7(0.1)$ \\
\hline & 10.46 & $58.4(0.3)$ & $11.8(1.9)$ & $28.4(1.3)$ & $0.9(0.4)$ \\
\hline & 20.93 & $47.9(5.8)$ & $11.8(3.0)$ & $37.9(2.2)$ & $1.4(0.3)$ \\
\hline & 31.39 & $43.0(4.3)$ & $12.0(1.4)$ & $41.5(3.0)$ & $2.2(1.3)$ \\
\hline \multirow[t]{4}{*}{ Schedule 2} & 0 & $63.1(1.5)$ & $10.0(1.0)$ & $25.0(0.8)$ & $0.5(0.1)$ \\
\hline & 10.46 & $57.4(6.1)$ & $9.6(1.4)$ & $29.5(5.0)$ & $1.0(0.2)$ \\
\hline & 20.93 & 48.7 (3.3) & $11.2(2.4)$ & $35.0(1.3)$ & $2.2(0.7)$ \\
\hline & 31.39 & $46.1(7.1)$ & $9.5(0.7)$ & $32.9(0.6)$ & $3.6(0.1)$ \\
\hline \multirow[t]{4}{*}{ Schedule 3} & 0 & $62.1(1.7)$ & $10.1(1.4)$ & $25.9(1.6)$ & $0.5(0.1)$ \\
\hline & 10.46 & $37.5(4.8)$ & $10.1(1.8)$ & $49.4(3.7)$ & $1.7(0.5)$ \\
\hline & 20.93 & 33.1 (2.5) & $8.8(1.3)$ & $51.8(2.9)$ & $4.9(2.1)$ \\
\hline & 31.39 & $31.8(4.6)$ & $9.6(0.9)$ & $52.9(5.2)$ & $5.4(0.9)$ \\
\hline
\end{tabular}

Data are mean, followed by SD in parentheses. 


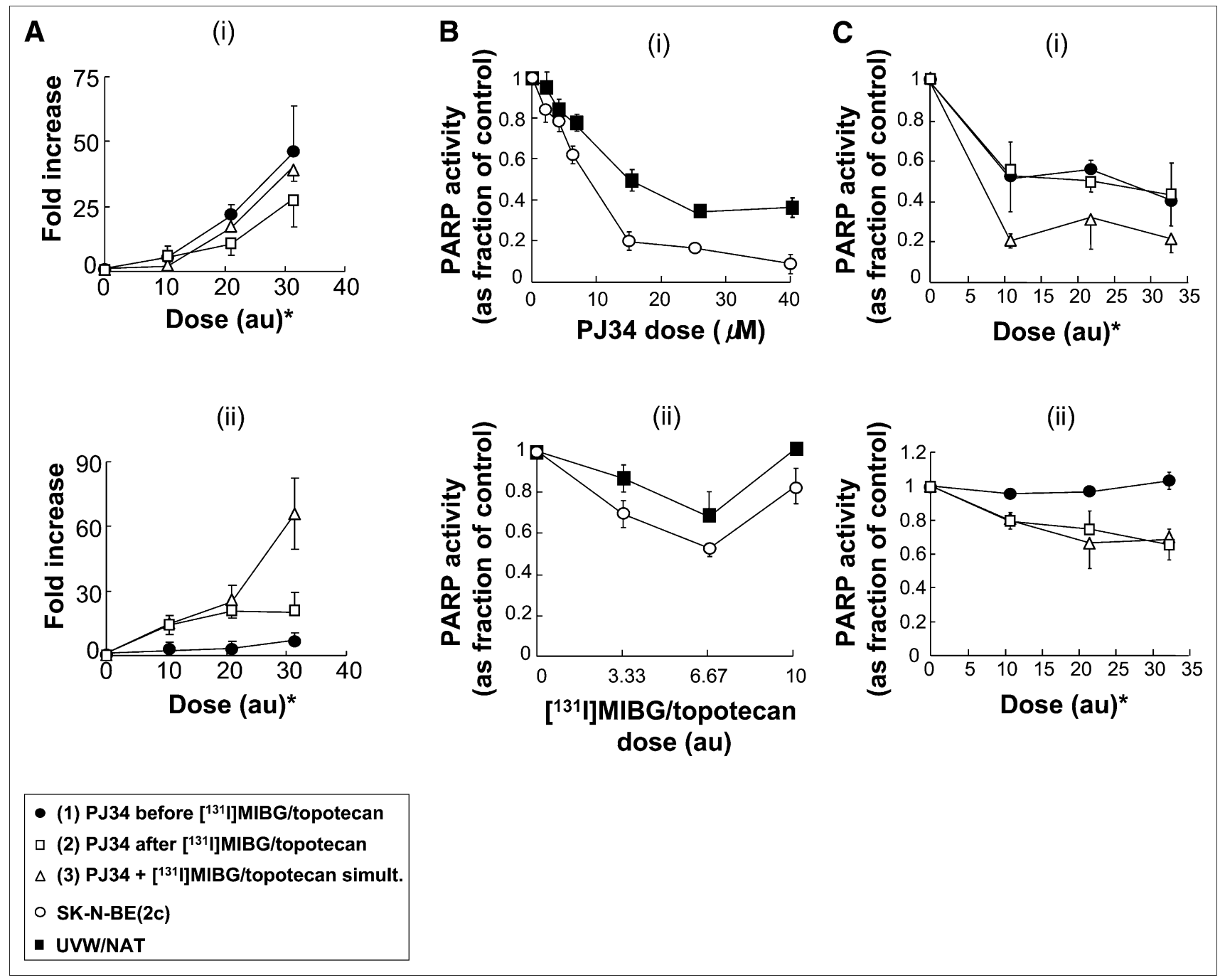

FIGURE 4. (A) $\gamma \mathrm{H} 2 \mathrm{~A}$.X analysis of dsDNA damage in SK-N-BE(2c) (i) and UVW/NAT (ii) cells. (B) PARP-1 activity in SK-N-BE(2c) and UVW/ NAT cells after PJ34 (i) and ${ }^{131} \mathrm{I}-\mathrm{MIBG} /$ topotecan (ii) treatment. (C) PARP-1 activity in SK-N-BE(2c) (i) and UVW/NAT (ii) cells after PJ34 and ${ }^{131}$ I-MIBG/topotecan combination treatment. Ratios of PJ34 and 131/-MIBG/topotecan used in 3-drug combinations were 31.97:1.29:8.8 and 29.1:2.76:10 for SK-N-BE(2c) and UVW/NAT cells, respectively. Ratios of ${ }^{131}$ I-MIBG and topotecan used in 2-drug combinations were 1.29:8.8 and 2.76:10 for SK-N-BE(2c) and UVW/NAT cells, respectively. Data are means and SD of triplicate determinations from 3 experiments.

enzyme to remove itself from cleaved DNA (31). PARP-1 also collaborates with Mre11, a core subunit of the Mre11/ Rad50/Nbs1 damage recognition complex, to promote replication fork restart after release from replication blocks (29). Thus, by counteracting topoisomerase I-induced DNA damage, PARP-1 activity acts as a positive regulator of genomic stability in eukaryotic cells.

It has previously been demonstrated that after the induction of DNA damage by $\mathrm{x}$-irradiation, ultraviolet light, and $\gamma$-irradiation, binding of PARP- 1 to Topo-I induces a rapid sequestration of Topo-I onto the sites of the DNA lesions $(20,32,33)$. Furthermore, Topo-I-mediated unwinding of supercoiled DNA is reduced after irradiation, possibly by abrogation of Topo-I catalytic activity $(34,35)$ or reduced longevity of Topo-I-DNA complexes (36). This effect appears to be due to PARP-1-induced ADP- ribosylation of Topo-I and is prevented by the addition of PARP-1 inhibitors $(34,35)$,

Therefore, in cells treated with combinations of ${ }^{131} \mathrm{I}-$ MIBG and topotecan, inhibition of PARP-1 activity by PJ34 leads to the simultaneous generation of multiple effects. Deregulation of Topo-I function via ADP-ribosylation and prevention of removal of topotecan-mediated aberrant TopoI-DNA adducts will enhance the efficacy of the Topo-I poison, whereas disruption of base excision repair and, potentially, HR mechanisms of repair would increase the effects of ${ }^{131}$ I-MIBG-induced DNA damage.

Treatment with ${ }^{131} \mathrm{I}-\mathrm{MIBG} /$ topotecan induced a reduction in PARP-1 activity, reaching a nadir at a combination dose equivalent to 5.05 and 6.36 au in SK-N-BE(2c) and UVW/ NAT cells, respectively. It has long been recognized that MIBG is an inhibitor of mono-ADP-ribosylation (37). Fur- 


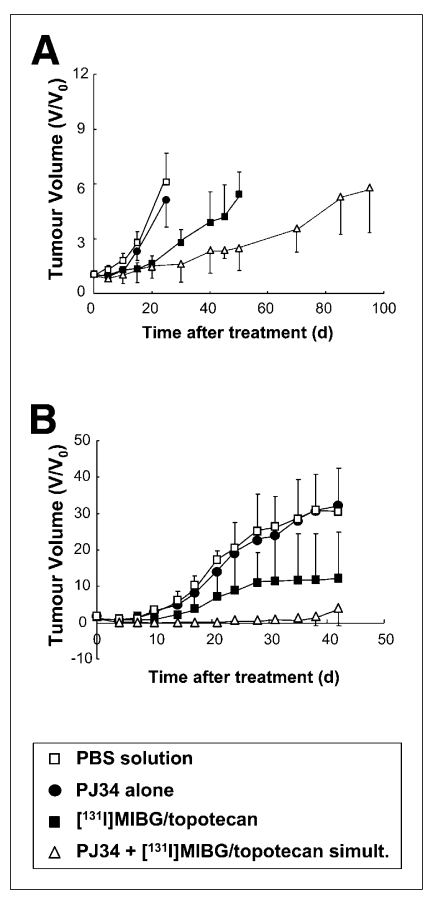

FIGURE 5. Effects of PJ34 and ${ }^{131}$ I-MIBG/TPT on SK-N$\mathrm{BE}(2 \mathrm{c})$ (A) and UVW/NAT (B) xenografts. Each treatment group consisted of 6 animals. Mice bearing SK-N-BE(2c) xenografts were treated with either $20 \mathrm{mg}$ of PJ34 per kilogram, $18 \mathrm{MBq}$ of ${ }^{131}$ |-MIBG plus $1.75 \mathrm{mg}$ of topotecan per kilogram, or combinations of PJ34 and ${ }^{131}$ I-MIBG/topotecan. UVW/ NAT-bearing animals were treated with either $20 \mathrm{mg}$ of PJ34 per kilogram, $5 \mathrm{MBq}$ of ${ }^{131} \mathrm{I}-$ MIBG plus $0.875 \mathrm{mg}$ of topotecan per kilogram, or 3-drug combinations.

thermore, it has recently been suggested that, in the absence of DNA damage, PARP-1 function is regulated by the mono-ADP-ribosyl polymerase activity of the related enzyme PARP-3 (38). Therefore, one possible explanation for these findings is that reduced PARP-1 function after administration of low doses of ${ }^{131} \mathrm{I}-\mathrm{MIBG} /$ topotecan is due to MIBG-induced inhibition of PARP-3 regulation of PARP1. However, after administration of doses of ${ }^{131} \mathrm{I}-\mathrm{MIBG} /$ topotecan greater than 5.05 au $(\mathrm{SK}-\mathrm{N}-\mathrm{BE}(2 \mathrm{c}))$ or $6.36 \mathrm{au}$ (UVW/NAT), PARP-1 function recovered in both cell lines. Increased DNA damage was observed with increasing dose of 3-drug therapy. Taken together, these results suggest that if, as speculated, MIBG inhibits PARP-3, increasing DNA damage may induce activation of PARP-1 via a PARP-3independent pathway, leading to the observed recovery of PARP-1 function after high-dose ${ }^{131}$ I-MIBG/topotecan treatment.

UVW/NAT cells treated with PJ34 before ${ }^{131}$ I-MIBG/ topotecan displayed no disruption of PARP-1 function. PJ34 induced a reduction of PARP-1 activity, which was restored by removal of the drug. The subsequent addition of ${ }^{131} \mathrm{I}-\mathrm{MIBG} /$ topotecan had no effect on PARP-1 function, suggesting that UVW/NAT cells were primed to resist ${ }^{131} \mathrm{I}$ MIBG/topotecan-induced disruption of PARP-1 activity by PJ34 pretreatment. It is possible that the recovery of PARP-1 function in PJ34 pretreated cells may be induced by a PARP3-independent pathway, which would be unaffected by PARP-3 inhibition by MIBG. This result suggests that the efficacy of $\mathrm{PJ} 34 /{ }^{131} \mathrm{I}-\mathrm{MIBG} /$ topotecan treatment may be affected by alternative PARP-1 activation pathways and warrants further study.

Although the involvement of PARP-1 in repair of dsDNA damage is as yet unclear, this present study does suggest that PARP-1 activity is involved in this process in some way. SK-N-BE(2c) cells, which exhibited reduced PARP-1 function in this phase, also displayed increased generation of dsDNA damage after 3-drug treatment, leading to supraadditive cytotoxicity. Conversely, UVW/NAT cells treated with PJ34 before ${ }^{131} \mathrm{I}-\mathrm{MIBG} /$ topotecan exhibited normal PARP-1 function and DNA damage was negligible, suggesting less inhibition of the repair of dsDNA breaks, leading to infraadditive toxicity in cells treated by this schedule. Combination therapy also induced $\mathrm{G}_{2} / \mathrm{M}$ arrest, in which the predominant dsDNA damage repair pathway is HR. Therefore, it is possible that PARP-1 may play a role in HR; however, involvement with nonhomologous end joining cannot be discounted.

PJ34 alone induced cytotoxicity and $\mathrm{G}_{2} / \mathrm{M}$ arrest. Therefore, nontarget effects may influence overall response. These nontarget effects will be addressed by further mechanistic studies, using PJ34 and also second- and third-generation inhibitors with greater PARP-1 specificity.

Previously, we demonstrated that ${ }^{131}$ I-MIBG/topotecan combination therapy significantly inhibited SK-N-BE(2c) and UVW/NAT tumor growth in vivo $(14,15)$. In this study, whereas PJ34 treatment alone had no effect on tumor growth, administration of PJ34 concurrently with ${ }^{131} \mathrm{I}-$ MIBG/topotecan significantly delayed the growth of SK$\mathrm{N}-\mathrm{BE}(2 \mathrm{c})$ and UVW/NAT xenografts, compared with ${ }^{131} \mathrm{I}-\mathrm{MIBG} /$ topotecan.

\section{CONCLUSION}

This study indicates that inhibition of PARP-1 has the potential to increase the efficacy of ${ }^{131} \mathrm{I}$-MIBG/topotecan

TABLE 4

Delayed Tumor Growth Resulting from Administration of PJ34 or ${ }^{131}$ I-MIBG/Topotecan Alone or in Combination

\begin{tabular}{|c|c|c|c|c|}
\hline \multirow[b]{2}{*}{ Treatment } & \multicolumn{2}{|c|}{ SK-N-BE(2c) tumors } & \multicolumn{2}{|c|}{ UVW/NAT tumors } \\
\hline & $\left(T_{2}\right)$ & Cure rate $(\%)$ & $\left(T_{10}\right)$ & Cure rate $(\%)$ \\
\hline PBS control & $10.23(1.62)$ & 0 & $18.26(3.94)$ & 0 \\
\hline PJ34 only & $11.23(2.61)$ & 0 & $18.45(3.55)$ & 0 \\
\hline 1311-MIBG/topotecan & $22.59(7.15)$ & 0 & $33.00(12.57)$ & 60 \\
\hline PJ34 plus ${ }^{131}$ I-MIBG/topotecan simultaneously & $25.96(9.56)$ & 0 & $>42$ & 100 \\
\hline Data are mean, followed by SD in parentheses. & & & & \\
\hline
\end{tabular}


combination therapy by increasing radiosensitivity and disrupting DNA repair. Taking into account the responses observed both in vitro and in vivo, this study suggests that enhancement of ${ }^{131} \mathrm{I}-\mathrm{MIBG} /$ topotecan efficacy may be best achieved by the simultaneous inhibition of PARP-1 function. Elucidation of the basis for resistance after pretreatment with PJ34 may allow further refinements to this combination and are worthy of investigation.

\section{DISCLOSURE STATEMENT}

The costs of publication of this article were defrayed in part by the payment of page charges. Therefore, and solely to indicate this fact, this article is hereby marked "advertisement" in accordance with 18 USC section 1734.

\section{ACKNOWLEDGMENTS}

This work was supported by grants from Cancer Research U.K., the Neuroblastoma Society, and Sparks. No other potential conflict of interest relevant to this article was reported.

\section{REFERENCES}

1. Cohn SL, Pearson AD, London WB, et al. The International Neuroblastoma Risk Group (INRG) classification system: an INRG Task Force report. J Clin Oncol. 2009;27:289-297.

2. Moroz V, Machin D, Faldum A, et al. Changes over three decades in outcome and the prognostic influence of age-at-diagnosis in young patients with neuroblastoma: a report from the International Neuroblastoma Risk Group Project. Eur J Cancer. 2011;47:561-571.

3. Pearson AD, Pinkerton CR, Lewis IJ, et al. High-dose rapid and standard induction chemotherapy for patients aged over 1 year with stage 4 neuroblastoma: a randomised trial. Lancet Oncol. 2008;9:247-256.

4. Matthay KK, Reynolds CP, Seeger RC, et al. Long-term results for children with high-risk neuroblastoma treated on a randomized trial of myeloablative therapy followed by 13-cis-retinoic acid: a children's oncology group study. J Clin Oncol. 2009;27:1007-1013.

5. Ladenstein R, Valteau-Couanet D, Brock P, et al. Randomized trial of prophylactic granulocyte colony-stimulating factor during rapid COJEC induction in pediatric patients with high-risk neuroblastoma: the European HR-NBL1/ SIOPEN study. J Clin Oncol. 2010;28:3516-3524.

6. Jaques S, Tobes MC, Sissons JC, Baker JA, Wieland DM. Comparison of the sodium dependence of uptake of meta-iodo-benzylguanidine and norepenephrine into cultured bovine adrenomedullary cells. Mol Pharmacol. 1984;26:539-546.

7. Mairs RJ, Livingstone AL, Gaze MN, Wheldon TE, Barrett A. Prediction of accumulation of ${ }^{131} \mathrm{I}$-meta-iodo-benzylguanidine in neuroblastoma cell lines by means of reverse transcription and polymerase chain reaction. $\mathrm{Br} \mathrm{J}$ Cancer. 1994;70:97-101.

8. Garaventa A, Guerra P, Arrighini A, et al. Treatment of advanced neuroblastoma with I-131meta-iodobenzylguanide. Cancer. 1991;67:922-928.

9. Voûte PA, Hoefnagel CA, de Kraker J, Valdés Olmos RA, Bakker DJ, van de Kleij AJ. Results of treatment with ${ }^{131}$ I-metaiodobenzylguanidine (131IMIBG) in patients with neuroblastoma: future prospects of zetotherapy. Prog Clin Biol Res. 1991;366:439-445.

10. Lashford LS, Lewis IJ, Fielding SL, et al. Phase I/II study of iodine 131metaiodobenzylguanidine in chemoresistant neuroblastoma: a United Kingdom Children's Cancer Study Group investigation. J Clin Oncol. 1992;10:1889-1896.

11. Gaze MN, Wheldon TE. Radiolabelled mIBG in the treatment of neuroblastoma. Eur J Cancer. 1996;32a:93-96.

12. Mairs RJ. Neuroblastoma therapy using radiolabelled [ $\left.{ }^{131} \mathrm{I}\right]$ meta-iodobenzylguanidine $\left(\left[{ }^{131} \mathrm{I}\right] \mathrm{MIBG}\right)$ in combination with other agents. Eur J Cancer. 1999;35: 1171-1173.

13. McCluskey AG, Boyd M, Gaze MN, Mairs RJ. [ $\left.{ }^{131} \mathrm{I}\right] \mathrm{MIBG}$ and topotecan: a rationale for combination therapy for neuroblastoma. Cancer Lett. 2005;228:221-227.
14. McCluskey AG, Boyd M, Ross SC, et al. $\left[{ }^{131} \mathrm{I}\right]$ meta-iodobenzylguanidine and topotecan combination treatment of tumours expressing the noradrenaline transporter. Clin Cancer Res. 2005;11:7929-7937.

15. McCluskey AG, Boyd M, Pimlott SL, Babich JW, Gaze MN, Mairs RJ. Experimental treatment of neuroblastoma using $\left[{ }^{131} \mathrm{I}\right]$ meta-iodobenzylguanidine and topotecan in combination. Br J Radiol. 2008;81(suppl):S28-S35.

16. Gaze MN, Chang YC, Flux GD, Mairs RJ, Saran FH, Meller ST. Feasibility of dosimetry-based high-dose ${ }^{131}$ I-meta-iodobenzylguanidine with topotecan as a radiosensitizer in children with metastatic neuroblastoma. Cancer Biother Radiopharm. 2005;20:195-199.

17. Oliver FJ, Menissier-de Murcia J, de Murcia G. Poly(ADP-ribose) polymerase in the cellular response to DNA damage, apoptosis, and disease. Am J Hum Genet. 1999;64:1282-1288.

18. Pieper AA, Verma A, Zhang J, Snyder S. Poly(ADP-ribose) polymerase, nitric oxide and cell death. Trends Pharmacol Sci. 1999;20:171-181.

19. Shall S, de Murcia G. Poly(ADP-ribose) polymerase-1: what have we learned from the deficient mouse model? Mutat Res. 2000;460:1-15.

20. Bauer PI, Chen H-J, Kenesi E, et al. Molecular interactions between poly(ADPribose) polymerase (PARP I) and topoisomerase I (Topo-I): identification of topology of binding. FEBS Lett. 2001;506:239-242.

21. Biedler JL, Roffler-Tarlov S, Schachner M, Freedman LS. Multiple neurotransmitter synthesis by human neuroblastoma cell lines and clones. Cancer Res. 1978;38:3751-3757.

22. Boyd M, Cunningham SH, Brown MM, Mairs RJ, Wheldon TE. Noradrenaline transporter gene transfer for radiation cell kill by ${ }^{131} \mathrm{I}$-meta-iodobenzylguanidine. Gene Ther. 1999;6:1147-1152.

23. Hunter DH, Zhu X. Polymer-supported radiopharmaceuticals: $\left[{ }^{131} \mathrm{I}\right] \mathrm{MIBG}$ and [123I]MIBG. J Labelled Comp Radiopharm. 1999;42:653-661.

24. Boyd M, Ross S, Owens J, et al. Preclinical evaluation of no-carrier-added $\left[{ }^{131} \mathrm{I}\right]$ meta-iodobenzylguanidine, for the treatment of tumours transfected with the noradrenaline transporter gene. Lett Drug Des Discov. 2004;1:50-57.

25. Vaidyanathan G, Zalutsky MR. No-carrier-added synthesis of meta-[131 I]iodobenzylguanidine. Appl Radiat Isot (Int J Radiat Appl Instrum. Part A). 1993; 44:621-628

26. Mairs RJ, Gaze MN, Barrett A. The uptake and retention of meta-iodo-benzyl guanidine by the neuroblastoma cell line NB1-G. Br J Cancer. 1991;64:293-295.

27. Chou TC, Talalay P. Quantitative analysis of dose-effect relationships: the combined effects of multiple drugs or enzyme inhibitors. Adv Enzyme Regul. 1984; 22:27-55.

28. Workman P, Twentyman P, Balkwill F, et al. United Kingdom Co-ordinating Committee on Cancer Research (UKCCCR) guidelines for the welfare of animals in experimental neoplasia, 2nd ed. Br J Cancer. 1998;77:1-10.

29. Bryant HE, Petermann E, Schultz N, et al. PARP is activated at stalled forks to mediate Mre11-dependent replication restart and recombination. EMBO J. 2009; 28:2601-2615.

30. Hall EJ, Giaccia AJ. Radiobiology for the Radiologist. Philadelphia, PA: Lippincott, Williams and Wilkins Publishers; 2011:54-66

31. Malanga M, Althaus FR. Poly(ADP-ribose) reactivates stalled DNA Topoisomerase I and induces DNA strand break resealing. J Biol Chem. 2004;279:52445248.

32. Boothman DA, Wang M, Scea RA, Burrows HL, Strickfaden S, Owens JK. Posttreatment exposure to camptothecin enhances the lethal effects of X-rays on radioresistant human malignant melanoma cells. Int J Radiat Oncol Biol Phys. 1992;24:939-948.

33. Thielmann HW, Popanda O, Staab H-J. Subnuclear distribution of DNA topoisomerase I and Bax protein in normal and Xeroderma pigmentosum fibroblasts after irradiation with UV light and $\gamma$ rays or treatment with topotecan. $J$ Cancer Res Clin Oncol. 1999;125:193-208.

34. Boothman DA, Fukunaga N, Wang M. Down-regulation of topisomerase I in mammalian cells following ionizing radiation. Cancer Res. 1994;54:4618-4626.

35. Smith HM, Grosovsky AJ. PolyADP-ribose-mediated regulation of p53 complexed with topoisomerase I following ionizing radiation. Carcinogenesis. 1999;20:1439-1443.

36. Smith LM, Willmore E, Austin CA, Curtin NJ. The novel Poly (ADP-ribose) polymerase inhibitor AG14361 sensitizes cells to topoisomerase I poisons by increasing the persistence of DNA strand breaks. Clin Cancer Res. 2005;11: 8449-8457.

37. Smets LA, Loesberg C, Janssen M, Van Rooij H. Intracellular inhibition of mono (ADP-ribosylation) by meta-iodobenzylguanidine: specificity, intracellular concentration and effects on glucocorticoid-mediated cell lysis. Biochim Biophys Acta. 1990;1054:49-55.

38. Loseva O, Jemth AS, Bryant HE, et al. PARP-3 is a mono-ADP-ribosylase that activates PARP-1 in the absence of DNA. J Biol Chem. 2010;285:8054-8060. 